\title{
ANÁLISE CRÍTICA DAS APLICAÇÕES DAS ESTRATÉGIAS DE COMUNICAÇÃO E MARKETING NA SÉRIE THE CRAZY ONES E SUA RELAÇÃO COM O MERCADO PUBLICITÁRIO CONTEMPORÂNEO
}

Critical Analysis of the communication and Marketing strategies application in The Crazy Ones Series and its relationship with the contemporary adverstising market.

Análisis crítico de las aplicaciones de estrategias de comunicación y marketing en la serie The Crazy Ones y su relación con el mercado publicitario contemporáneo.

Luiz Guilherme de Brito Arduino Publicitário, Mestrando em Linguística Aplicada pela Universidade de Taubaté luiz.gbarduino@unitau.br

Vânia de Moraes Doutora em Comunicação e Semiótica, docente dos cursos de graduação e Mestrado em Linguística Aplicada da Universidade de Taubaté. vania.unitau@gmail.com

\section{Resumo}

A série The Crazy Ones aborda, em diversos episódios, situações e conflitos relacionados com a prática da atividade publicitária. Assim, o objetivo desta pesquisa foi de discutir as estratégias de marketing de guerrilha e propaganda para gestão de crise apresentadas em um episódio da série com o intuito de analisar criticamente suas aplicações e relacionar com o mercado publicitário contemporâneo. Foram identificados problemas nas aplicações das estratégias, havendo possíveis ponderações para suas aplicações na atualidade.

Palavras-chave: The Crazy Ones. Análise crítica. Estratégias.

\section{Abstract}

In several episodes, The Crazy Ones series approaches situations and conflicts related to the practice of the advertising activity. The purpose of this research was to discuss the advertising and guerrilla marketing strategies for the management of crisis presented in one of the series' episode with the purpose of critically analyzing its applications and associate them with the contemporary advertising marketing. Problems were identified in the application of strategies, and there are possible considerations that concern their use nowadays.

Key words: The Crazy Ones. Critical analysis. Strategies. 


\section{Resumen}

La serie The Crazy Ones aborda, en varios episodios, situaciones y conflictos relacionados con la práctica de la actividad publicitaria. Por lo tanto, el objetivo de esta pesquisa fue discutir las estrategias de marketing de guerrilla y propaganda para la gestión de crisis presentadas en un episodio de la serie para analizar críticamente sus aplicaciones y relacionarse con el mercado publicitario contemporáneo. Fueran identificados problemas en las aplicaciones de las estrategias, con posibles ponderaciones para sus aplicaciones en la actualidad.

Palabras clave: The Crazy Ones. Análisis critica. Estratégias.

\section{INTRODUÇÃO}

A temática da publicidade e da propaganda pode ser encontrada em diversos filmes e séries de $\mathrm{TV}^{1}$. Nesses casos, normalmente, são retratando o perfil do publicitário e a utilização das estratégias de propaganda em contextos socioculturais diversos.

No que diz respeito às séries de TV com a temática publicitária, podemos destacar algumas produções, nos últimos anos, entre elas a série The Crazy Ones, objeto de estudo desta pesquisa.

A série The Crazy Ones é uma narrativa ficcional que retrata o dia a dia de uma agência de publicidade chamada Roberts \& Roberts liderada por Simon Roberts e sua filha, Sydney Roberts. Na série, a agência presta serviços de comunicação e marketing para marcas mundialmente conhecidas. Em alguns episódios, são evidenciadas falhas no planejamento estratégico das ações propostas pela agência, acarretando situações conflitantes, como é o caso do segundo episódio - intitulado como "Espetacular" - no qual foram trabalhadas as estratégias de marketing de guerrilha e propaganda para gestão de crise. As estratégias foram trabalhadas de forma indevida, causando a necessidade de readequação das ações.

O planejamento de campanha é fundamental para evitar problemas nas ações de comunicação e marketing. O planejamento é uma ferramenta administrativa, destinada a avaliar os melhores caminhos para o processo de ações de comunicação. Para Simões (1992) o planejamento tem uma finalidade ordenadora e coordenadora, uma análise que permite medir os resultados atingidos, evitando riscos.

\footnotetext{
${ }^{1}$ Seabra (2016) conceitua as séries como um programa de TV que se diferencia da minissérie e da telenovela, de um soap opera, reality show, game show ou talk show e não tem caráter jornalístico. Entretanto, com o avanço da tecnologia, novas formas de consumir conteúdo mudaram o cenário de se assistir a séries de TV. Consumidas por meio do streaming - o termo indica o fluxo de conteúdos multimídia transmitido, podendo ser observado no consumo de filmes, séries, músicas e jogos disponíveis na internet, o termo séries de TV passa a ser considerado também como "séries", pois, não são consumidas somente pela TV.
} 
Partindo da premissa de que o segundo episódio da série The Crazy Ones retrata problemas que possam ocorrer no dia a dia das agências de publicidade e propaganda, especificamente, no que se refere a falta de planejamento nas ações de comunicação e marketing, esta pesquisa pretende responder o seguinte questionamento: Como as estratégias de comunicação e marketing foram aplicadas no segundo episódio da série The Crazy Ones?

Desta forma, este trabalho tem como objetivo geral levantar as estratégias de marketing de guerrilha e propaganda para gestão de crise, apresentadas no segundo episódio da série The Crazy Ones, com o intuito de analisar criticamente suas aplicações, relacionandoas com o mercado publicitário contemporâneo. Trata-se de uma pesquisa de caráter qualitativo, fundamentada na análise de conteúdo.

\section{REFERENCIAL TEÓRICO}

Nessa primeira parte da pesquisa, apresentamos a fundamentação teórica sobre marketing e planejamento para gestão de crise.

\subsection{Marketing: algumas definições}

A Associação Americana de Marketing considera que o marketing é uma atividade composta por um conjunto de processos que envolvem a comunicação, a criação e a entrega de oferta de produtos e serviços que tenham valor para os clientes. Kotler (2000, p.30) define Marketing como "um processo social por meio do qual pessoas e grupos de pessoas obtêm aquilo de que necessitam e o que desejam com a criação, oferta e livre negociação de produtos e serviços de valor com outros".

O marketing não é uma atividade aleatória, ele exige um planejamento cuidadoso com ênfase nas implicações éticas para qualquer decisão tomada em relação à sociedade. No planejamento de marketing é importante constar: "como o bem ou o serviço será concebido e projetado, quanto custará, onde e como será promovido e como chagará ao consumidor" (GREWAL e LEVY, 2012 p.5).

Para Beraldo (2017), um bom planejamento de marketing possibilita que os investimentos das empresas sejam usados de forma assertiva para conquistar e fidelizar clientes, anunciar a marca e, consequentemente, alavancar os negócios.

Entre as mais diversas variações de marketing, destaca-se o marketing de guerrilha, foco de estudo desta pesquisa. Levinson $(1986$, p. 9) afirma que o marketing de guerrilha pode ser definido como "um método que utiliza as mais recentes estratégias de guerrilha no 
campo de marketing, para planejar, lançar e manter a maior ofensiva mercadológica possível”. Cavalcante (2003) sugere que o marketing de guerrilha possui um arsenal de conceitos e ideias para que as empresas possam sobreviver em meio a um mercado desigual e competitivo. Para ele, o marketing de guerrilha é alimentado pela criatividade, uma vez que sua aplicação tem a finalidade de impactar o consumidor de forma alternativa e diferenciada. Nesse sentido, as técnicas de guerrilha proporcionam para as empresas oportunidades de ações de impacto e baixo custo, valendo-se de expertise e criatividade dos profissionais envolvidos (RODRIGUES, 2010).

Toda a estratégia de marketing, sobretudo do marketing de guerrilha, deve seguir rigorosamente o planejamento estratégico, considerando as inúmeras variáveis. Caso isso não aconteça, as falhas nas ações podem causar crise para a marca, sendo necessário, readaptação do planejamento em busca das possíveis soluções.

\subsection{Planejamento de Gestão de Crise}

O planejamento de gestão de crise é um processo que visa minimizar, reduzir ou, se possível, eliminar os impactos causados por uma adversidade dentro da empresa - seja ela legal, social, financeira ou de qualquer outra natureza. Para Nascimento (2007) as empresas, muitas vezes, se deparam com situações que saem da rotina para as quais ainda não estão preparadas para lidar. Nesse sentido, torna-se necessário um planejamento que visa a soluções cabíveis, para não abalar sua imagem e reputação. Kunsch (2006) afirma que a atuação de um profissional de comunicação na gestão de crise é de extrema importância, uma vez que é ele quem " deve assumir a responsabilidade pela coleta de informações e pela organização dos contatos com a imprensa e com os públicos de interesse" (KUNSCH, 2006, p.235-6). São os profissionais de comunicação que devem planejar e monitorar o modo como a informação é levada ao público, nas mais diversas perspectivas, tanto pela empresa como pela mídia; e também, a própria relação de empresa com seu público interno (funcionários e colaboradores), com o propósito de zelar pela sua imagem.

Para Nascimento (2007), atuar com o gerenciamento de crises é importante para toda e qualquer empresa, visto que "a atividade deve ser constante e evoluir junto às necessidades da organização, trabalhando sempre a ideia de que erros podem ser corrigidos, mas o melhor é que sejam evitados" (NASCIMENTO, 2007.p.19). Nesse contexto, a propaganda deve ser utilizada como uma solução para contornar uma crise, sendo específica para o público 
determinado da empresa. Anúncios impressos, ações internas e externas e eventos podem contribuir de forma estratégica para manter a imagem e reputação de uma empresa.

\section{METODOLOGIA}

Para analisar, qualitativamente, as estratégias de marketing de guerrilha e a propaganda para gestão de crise, apresentadas no segundo episódio da série The Crazy Ones, foi desenvolvida uma estrutura de análise fundamentada na análise de conteúdo.

A análise de conteúdo refere-se a um conjunto de instrumentos metodológicos que se aplicam a discursos diversificados. Moraes (1999, p.2) ressalta que a "matéria-prima da análise de conteúdo pode constituir-se de qualquer material proveniente da comunicação verbal ou não-verbal, como cartas, cartazes, jornais, revistas, informes, livros, filmes, “. Essa metodologia de pesquisa faz parte de uma estratégia teórica e prática de análise, com um significado especial no campo das investigações sociais. Seus métodos de investigação favorecem a leitura crítica das mensagens.

Para Bardin (2016) a análise de conteúdo é pautada na pré-análise; descrição e exploração do material; análise dos resultados que inclui inferências e interpretações. Tomando como base esses pressupostos de organização, apresentaremos a seguir a análise do segundo episódio da série The Crazy Ones.

\subsection{Pré- análise}

Para o processo de preparação e identificação das amostras a serem analisadas, foram elaborados quadros que possibilitam classificar e apresentar o conteúdo, facilitando assim, a análise crítica. A estrutura elaborada é composta pela sinopse do episódio, a descrição das estratégias de comunicação e marketing abordadas no episódio; apresentação de algumas cenas; análise contextualizada dos problemas apresentados, conforme segue:

\section{A) Sinopse do Episódio}

A apresentação da sinopse do episódio permite uma melhor compreensão da narrativa, reunindo os aspectos essenciais do enredo.

B) Estrutura de Identificação e descrição das estratégias de comunicação e marketing abordadas no episódio "x" da série The Crazy Ones. 


\begin{tabular}{|l|}
\hline I) FICHA TÉCNICA \\
\hline Apresentar a ficha técnica do episódio a ser analisado. \\
\hline II) ESTRATÉGIAS \\
\hline $\begin{array}{l}\text { Apresentar quais estratégias de comunicação e marketing foram abordadas no episódio } \\
\text { analisado. }\end{array}$ \\
\hline III) DESCRIÇÃO \\
\hline $\begin{array}{l}\text { Descrever como foram aplicadas as estratégias de comunicação e marketing presentes no } \\
\text { episódio analisado. }\end{array}$ \\
\hline D) RESULTADOS DAS APLICAÇÕES DAS ESTRATÉGIAS NA SÉRIE \\
\hline Apresentar os resultados das estratégias abordados na série. \\
Quadro 01 - Estrutura de Identificação e descrição das estratégias de comunicação e marketing abordadas no \\
episódio e série selecionada.
\end{tabular}

Fonte: Arduino, 2018.

\section{C) Leitura Crítica: Apresentações de algumas cenas e considerações gerais}

Após a identificação e descrição das estratégias, o autor realizará a leitura crítica apresentando algumas cenas da série, discutindo os tópicos importantes considerados pelo mesmo.

\section{D) Síntese dos problemas apresentados no episódio e possibilidades de aplicações}

Neste momento, será realizada uma síntese dos problemas apresentados no tópico anterior e a verificação das possibilidades de aplicação das estratégias analisadas e discutidas.

Estratégia 1: Nome da estratégia identificada.

\begin{tabular}{|c|c|}
\hline Problemas identificados & Considerações para aplicação \\
\hline $\begin{array}{l}\text { Aqui serão apresentadas as problemáticas } \\
\text { identificadas no episódio a respeito das } \\
\text { estratégias de comunicação e marketing. }\end{array}$ & $\begin{array}{l}\text { Aqui serão apresentadas as soluções para que } \\
\text { estas estratégias possam ser aplicadas, } \\
\text { conforme todo o conhecimento teórico e as } \\
\text { demais análises já realizadas. }\end{array}$ \\
\hline
\end{tabular}

Quadro 02 - Estrutura do Quadro de Identificação dos problemas no episódio "x" em relação à estratégia de "x" e as considerações para a sua aplicação.

Fonte: Arduino, 2018.

\section{E) Case}

Neste tópico, serão apresentados dois cases de campanhas atuais, que trabalham com o marketing de guerrilha e estratégias de gestão de crise. 
- Marketing de Guerrilha realizado pela empresa Procter \& Gamble (P\&G) dos Estados Unidos.

- Campanha da empresa Burger King "Flame Grilled since 1954".

\section{DESCRIÇÃO DO MATERIAL E ANÁLISE CRÍTICA DOS RESULTADOS}

\section{Episódio 2- "Espetacular"}

\section{a) Sinopse do Episódio}

A diretora de criação, Sidney Roberts, apresenta uma campanha de mídia exterior para os empresários da marca de café Windy City Coffee. Eles, insatisfeitos com a proposta, pediram algo surpreendente. Simon Roberts propõe, então, uma campanha pautada na estratégia de marketing de guerrilha. Durante a ação, alguns imprevistos (causados por intemperes do tempo) ocorreram. A situação fugiu de controle e logo a notícia se espalhou pelas mídias, denegrindo a imagem da marca. Para solucionar o problema, foi necessário trabalhar com a estratégia de Propaganda para Gestão de Crise.

A cena a seguir ilustra o momento em que Sidney Roberts apresenta a campanha para os representantes da marca Windy City Coffe.

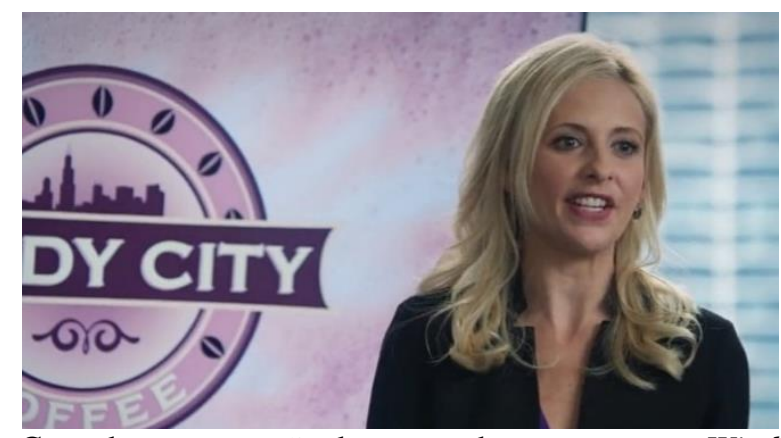

Figura 01 - Cena de apresentação da campanha para a marca Windy City Coffee Fonte: The Crazy Ones, 2013.

Sidney Roberts aparenta segurança durante a apresentação da campanha, porém, a ambientação fria (tons de lilás e azul) endossa a falta de originalidade nas ações.

b) Estrutura de Identificação e descrição das estratégias de comunicação e marketing abordadas no episódio "Espetacular” da série The Crazy Ones.

I) FICHA TÉCNICA

O episódio "Espetacular" foi produzido em parceria com Aaron Greenberg. Fizeram parte ainda o 
diretor de fotografia Byron Shah; designer de produção, Michael Wylie; editor, Steven Sprung; diretor de arte, Lori Agostino; primeiro assistente de direção de arte, Steohen D’Amato; segundo assistente de direção de arte, Robin Bronner; casting, Ken Miller. Fizeram parte do: Robbin Willians, no papel Simon Roberts; Sarah Michelle Gellar, como Sydney Roberts; Amanda Setton interpretou Lauren Stotsky; James Wolk foi Zach Cropper e Hamish Linklater deu vida a Andrew Keanelly.

\section{II) ESTRATÉGIAS}

Este episódio apresenta duas estratégias publicitárias. A primeira consiste em utilizar o Marketing de Guerrilha com o intuito de impactar os clientes e promover a marca da empresa de café Windy City Coffee; e a segunda é a utilização da Propaganda para Gestão de Crise, que busca solucionar um problema ocasionado durante a realização da estratégia de marketing de guerrilha.

III) DESCRIÇÃO

Após a apresentação da divulgação da marca Windy City Coffee em mídia exterior, os clientes solicitam uma estratégia mais ousada para Sydney Roberts. Ela, então, propõe a realização de uma campanha utilizando a estratégia de marketing de guerrilha. A peça, pautada numa intervenção urbana, consiste em colocar na praça Daley, em Chicago, uma xícara gigante, derramando café em um grande copo. O intuito da ação seria a promoção da marca por meio da experimentação dos produtos oferecidos; assim como, a obtenção de uma cobertura jornalística sobre tal evento. Num primeiro momento, a abordagem colocada em prática foi um sucesso; porém, uma ventania acabou transformando a ação em um fracasso. Ao ventar, o café começa a espalhar-se e molhar as pessoas presentes no local. A notícia repercute na imprensa, prejudicando a imagem da marca. Após esta tensão, Sidney pensa em uma forma de reverter o problema. Ela decide usar uma estratégia de gestão de crise. Tomando como base o comentário de uma jornalista que diz "Era como algo saído de um filme de terror", Sidney resolve trabalhar com o conceito de que o café da marca Windy City Coffee é "perigosamente bom". Os representantes da marca aprovam a campanha e o problema é solucionado.

\section{D) RESULTADOS DAS APLICAÇÕES DAS ESTRATÉGIAS NA SÉRIE}

No episódio, os clientes aprovam a campanha, utilizando tanto a primeira estratégia (marketing de guerrilha), quanto à segunda (propaganda para gestão de crise). É válido ressaltar que a estratégia de gestão de crise só foi realizada porque a estratégia de marketing de guerrilha apresentada pela agência apresentou uma falha que teve grande repercussão.

Quadro 03 - Quadro de Identificação e descrição das estratégias de comunicação e marketing abordadas no episódio 2 da série The Crazy Ones

Fonte: Arduino, 2018. 


\section{c) Apresentações das cenas e suas considerações}

Sidney, juntamente com Simon, apresentam uma campanha para a marca Windy City Coffee, propondo uma comunicação em mídia exterior, especificamente em outdoor e em pontos de ônibus, a fim de sensibilizar o público em relação à marca e aumentar as vendas. Entretanto, os clientes solicitam uma estratégia emocionante e mais ousada.

$\mathrm{Na}$ tentativa de atender à solicitação dos representantes da marca, Sydney propõe uma estratégia de marketing de guerrilha, a qual consiste em colocar na praça Daley, em Chicago, uma xícara gigante derramando café em um grande copo (conforme cena apresentada na imagem a seguir), visando à promoção da marca e realizando uma experimentação do produto para os consumidores em potencial. Os organizadores da ação acreditavam que, por se tratar de algo inovador, a estratégia de marketing ganharia espaço gratuito em diversas mídias gerando, inclusive, uma cobertura jornalística com comentários positivos.

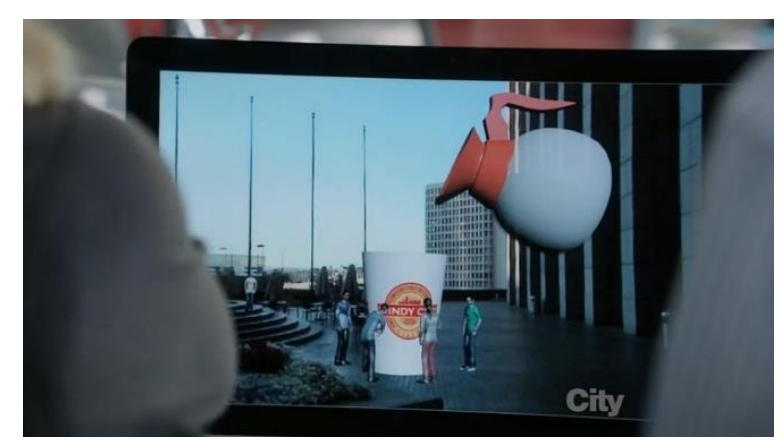

Figura 02 - Cena em que Sydney apresenta a da campanha para seu grupo na agência. Fonte: The Crazy Ones, 2013.

A ideia de usar o marketing de guerrilha ajustado em uma ação criativa atenderia à necessidade do cliente. Conforme já discutido, em um mercado competitivo, utilizar a estratégia de marketing de guerrilha proporciona para as empresas uma "arma" mais barata e eficaz, valendo-se de sua expertise e criatividade, trazendo grande visibilidade para as marcas.

$\mathrm{Na}$ data estabelecida, a ação de marketing de guerrilha é colocada em prática. De início, tudo ocorre conforme o planejado; no entanto, uma súbita ventania invade o local e faz com que o café se espalhe e seja jogado nas pessoas presentes (conforme ilustrado na imagem a seguir), que transitavam no local. Neste momento, percebe-se uma fragilidade na realização da estratégia. 


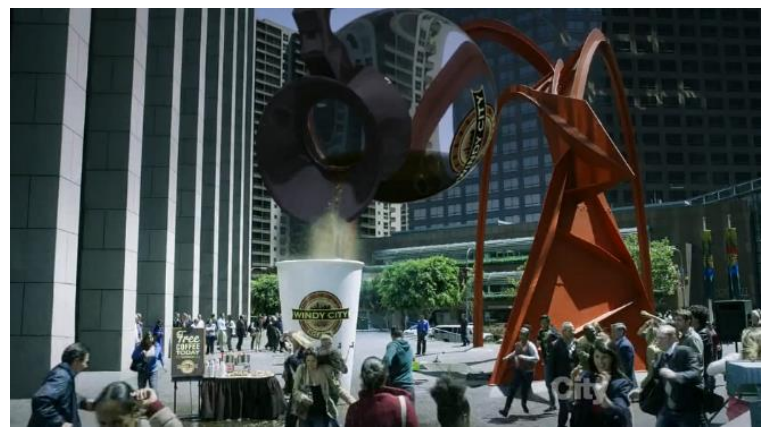

Figura 03 - Cena em que é espirrado café nas pessoas em praça pública.

Fonte: The Crazy Ones, 2013.

Para a realização de uma estratégia de comunicação e marketing, é importante estudar todo o cenário com o intuito de prever possíveis percalços. No que se refere a uma intervenção urbana ao ar livre, é necessário visitar o local por diversas vezes, analisando o fluxo de pessoas, os espaços disponíveis, as variáveis climáticas, entre outras questões relacionadas ao ambiente como um todo.

No caso da estratégia apresentada, não foi prevista a catástrofe causada pelo vento, acarretando uma exposição negativa para a o cliente e, consequentemente, para a agência. É fato que as questões climáticas nem sempre são previsíveis, por esse motivo o perigo de se arriscar uma estratégia de marketing em espaços públicos é trazer riscos para a segurança de quem transita pelo local.

Preocupada com a repercussão negativa da estratégia proposta pela agência, Sydney busca soluções para amenizar a crise.

A partir do comentário aterrador feito por um jornalista - "Era como algo saído de um filme de terror" -, Sidney tem a ideia de trabalhar uma campanha evidenciando um novo conceito para a marca Windy City Coffee: o de que o café é "perigosamente bom".

A cena, retratada a seguir, mostra Sidney apresentando para o cliente o novo conceito para a marca. As grades indicam que todos estão "enjaulados" em busca de uma solução para a crise instalada. 


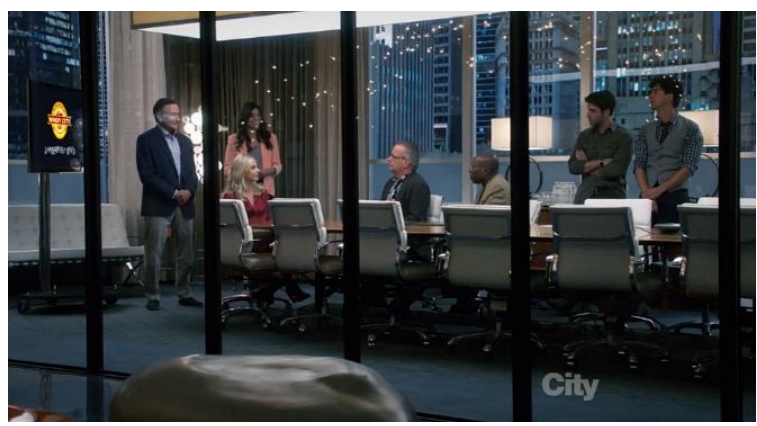

Figura 04 - Cena em que é exibido a campanha final para os clientes. Fonte: The Crazy Ones, 2013.

Finalmente, os representantes da marca aprovam a campanha e o problema é solucionado.

Cabe ressaltar que, conforme Nascimento (2007), a gestão de crise é definida como uma atividade de gestão da imagem e reputação de uma empresa, trabalhando sempre a ideia de que erros podem ser corrigidos, mas o melhor é que sejam evitados.

Tomando como base o referencial teórico apresentado neste trabalho, podemos considerar que a estratégia de marketing de guerrilha apresentada neste episódio da série foi criativa, atendendo a finalidade de impactar o consumidor de forma alternativa e diferenciada. Entretanto, tal estratégia apresentou falhas que colocaram em risco a imagem da marca.

No que se refere à estratégia de gestão de crise - que aproveitou o próprio acontecimento para dar um novo conceito a marca -, podemos dizer que atingiu o objetivo. Segundo Nascimento (2007), tratando-se do gerenciamento de crises, é importante trabalhar sempre a ideia de que erros podem ser corrigidos.

Após a realização da leitura crítica de tópicos de discussão a respeito de como foram conduzidas as estratégias no episódio da série, neste momento, serão apresentadas as possibilidades de aplicações das estratégias identificadas e analisadas anteriormente, as quais são marketing de guerrilha (estratégia 1) e propaganda para gestão de crise (estratégia 2) destacando algumas considerações.

\section{d) Síntese dos problemas apresentados no episódio e possibilidades de aplicações}

Após a realização da leitura crítica de tópicos de discussão a respeito de como foram conduzidas as estratégias no episódio da série, neste momento, serão apresentadas as possibilidades de aplicações das estratégias identificadas e analisadas anteriormente, as quais são marketing de guerrilha (estratégia 01) e propaganda para gestão de crise (estratégia 02) destacando algumas considerações. 
Estratégia 01: Marketing de Guerrilha

O quadro a seguir, retrata a ação de Marketing de Guerrilha apresentada no Segundo Episódio da Série.

\begin{tabular}{|l|l|}
\hline Problemas identificados & Considerações para aplicação \\
\hline A) Falta de atenção ao planejamento & $\begin{array}{l}\text { Ao planejar uma ação de marketing de } \\
\text { guerrilha, é importante prever as mais } \\
\text { diversas situações que podem prejudicar ou } \\
\text { impedir a sua realização; tais como leis e } \\
\text { regulamentos (o que se pode ou não fazer e } \\
\text { em quais condições), segurança (se uma ação } \\
\text { trouxer riscos, deve ser verificado sua } \\
\text { aplicação) e fatores ambientas (atentar-se aos } \\
\text { elementos e condições climáticas, como o } \\
\text { vento, sol, chuva, calor, frio). O } \\
\text { planejamento deve ser realizado, dando } \\
\text { atenção a esses requisitos para que seja } \\
\text { aplicado de forma apropriada. }\end{array}$ \\
\hline
\end{tabular}

Quadro 04 - Estratégia de Marketing de Guerrilha e as considerações para a sua aplicação.

Fonte: Arduino, 2018.

A estratégia de Marketing de Guerrilha pode ser considerada uma solução em relação à visibilidade, criatividade e posicionamento de uma marca a fim de impactar o público.

Normalmente, as ações criativas são compartilhadas por diversas mídias, gerando uma grande oportunidade para que a marca e suas ações se tornem mais visíveis para a sociedade.

Case: Marketing de Guerrilha realizado pela empresa Procter \& Gamble (P\&G) dos Estados Unidos.

A primeira estratégia utilizada neste episódio da série The Crazy Ones é o marketing de guerrilha, que, em suas diversas modalidades, tem a finalidade de impactar o consumidor de forma alternativa, conforme já discutido. 


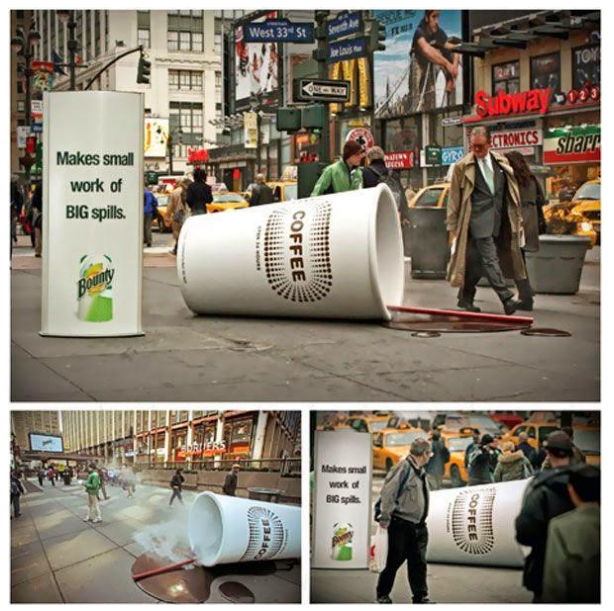

Figura 05 - Procter \& Gamble: Café gigante nas ruas de Nova Iorque.

Fonte: IBE Business Education FGV. Disponível em: < http://ibefgv.blogspot.com/2014/05/marketing-deguerrilha-7-cases-de.html>. Acesso em 16 de setembro de 2019.

A empresa Procter \& Gamble $(\mathrm{P} \& \mathrm{G})$ utilizou o marketing de guerrilha para promover a sua linha de papel toalha da marca Bounty. Um exemplo desse tipo de ação foi a xícara de seis metros de altura derrubada e derramando café sobre a calçada, a qual tinha vapor e aroma de café feito na hora, colocada nas ruas de Nova Iorque.

Observa-se que foi utilizada nesta ação de marketing de guerrilha a intervenção urbana, sendo uma das modalidades que busca impactar os consumidores em potencial.

Estratégia 02: Propaganda para gestão de crise.

A seguir, apresentaremos um quadro de identificação dos problemas de gestão de crise, retratados no Segundo Episódio.

\begin{tabular}{|c|l|}
\hline Problemas identificados & Considerações para aplicação \\
\hline A) Nada & Nada. \\
& \\
\hline
\end{tabular}

Quadro 05 - Propaganda para gestão de crise e as considerações para a sua aplicação. Fonte: Arduino, 2018.

No episódio, observa-se que os publicitários utilizaram a propaganda como estratégia para resolver um problema que, por falta de atenção, acabou prejudicando a agência e principalmente o cliente. Desta forma, a agência resolveu criar uma propaganda utilizando as cenas gravadas do acontecimento, divulgadas pelo jornal, utilizando a situação negativa em uma oportunidade. Em casos como esse, todo o cenário histórico da marca, imagem e 
reputação deve ser analisado para definir qual ação tomar. Este processo não é apresentado na série; entretanto, para a realização no contexto atual, esse processo deve ser executado. É válido ressaltar que é importante que a agência também realize um estudo para tomadas de decisões que favoreçam e trabalhem a sua própria imagem e reputação perante aos seus clientes, seus prospects ${ }^{2}$ e a sociedade que acaba assistindo todo este cenário.

Case: Campanha da empresa Burger King "Flame Grilled since 1954".

No ano de 2017, o Burger King lançou uma campanha cujo objetivo era mostrar a importância de seu método de fazer as carnes, uma vez que seus hambúrgueres são grelhados no fogo e não fritos na chapa, como fazem os seus concorrentes. Desta forma, utilizando de um acontecimento próprio, a marca abordou na campanha, por meio de fotos reais, os restaurantes que pegaram fogo desde 1954, mostrando restaurantes na Itália, no Oregon e na Pensilvânia. Tendo por base que o motivo principal do incêndio foi a utilização do fogo para grelhar as carnes, a campanha desenvolvida pela agência DAVID Miami, retrata o conceito "Flame Grilled since 1954" (Grelhado em chamas desde 1954), que traz três restaurantes do Burger King que foram incendiados. Tal conceito trabalhado pela agência, tem como origem o próprio discurso da marca ao se apresentar como diferencial, por ter as carnes dos hambúrgueres grelhados.

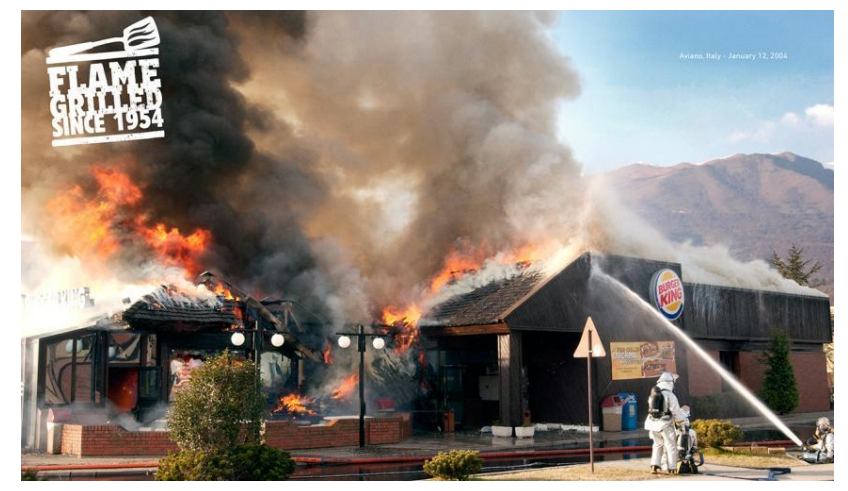

Figura 06 - Campanha “Flame Grilled Since 1954” da marca Burger King.

Fonte: Sapo.Shifter. Disponível em: < https://shifter.sapo.pt/2017/02/o-burger-king-esta-em-brasa-em-maisuma-campanha-incrivel/ > . Acesso em 16 de setembro de 2018.

Neste contexto, percebe-se que a estratégia da propaganda não foi utilizada de forma isolada, mas em um conceito já trabalhado pela marca, realizando uma gestão da crise com a

\footnotetext{
${ }^{2}$ Prospects são os clientes que têm maior chance de comprar da empresa determinado produto e que possuem maior valor para a empresa.
} 
qual ela já havia se deparado anos atrás. Assim, observa-se que a propaganda como estratégia para gestão de crise já foi utilizada, alcançando resultados satisfatórios em relação à imagem e reputação de uma marca. E para isso, é importante que haja um estudo do caso para as tomadas de decisões corretas, as quais proporcionarão benefícios para a marca.

\section{CONSIDERAÇÕES}

A presente pesquisa analisa criticamente ações de marketing de guerrilha e as estratégias para gestão de crise, retratadas no segundo episódio da série The Crazy Ones, apresentando um contraponto com campanhas publicitárias contemporâneas.

Com resultado das análises, considera-se que houve falhas na elaboração do planejamento. A ação de marketing de guerrilha, pautada em uma intervenção urbana instalação de um café gigante em uma praça pública - foi criativa. Entretanto, a falta de planejamento da ação acarretou transtornos que poderiam denegrir a imagem da empresa patrocinadora. Com o intuito de evitar que a imagem negativa em relação à marca prevalecesse, perante a opinião pública, foi desenvolvida uma ação para gerenciamento de crise. Com a análise do conteúdo apresentado, concluímos que as ações de marketing de guerrilha e estratégias de gerenciamento de crise, podem e devem ser aplicadas - conforme foram exemplificadas por meio dos cases que fazem parte do mercado publicitário contemporâneo. Entretanto, compete aos profissionais da área de comunicação e marketing, planejar as ações de forma criteriosa, avaliando as inúmeras variantes que possam acarretar riscos na implementação das estratégias.

\section{REFERÊNCIAS}

ARDUINO, Luiz Guilherme de Brito. Leitura Crítica: estudo das estratégias de comunicação e marketing abordadas na série The Crazy Ones, 2018. Trabalho de Conclusão de Curso (Graduação) Universidade de Taubaté (UNITAU), Taubaté, 2018.

BAHIANA, A. Como ver um filme. RJ: Nova Fronteira, 2012.

BARDIN, Laurence. Análise de conteúdo. São Paulo: Edições, 2016.

BERALDO, Flávio. Tipos de Marketing - Os principais e suas estratégias. Disponível em: 〈https://blog.cicloagenciadigital.com.br/tipos-de-marketing/>. Acesso em: 23 de novembro de 2019.

BRAGA, José Luiz. O sistema social crítico interpretativo. In: PRADO, José Luiz Aidar (org). Crítica das práticas midiáticas: da sociedade de massas às ciberculturas. São Paulo: Hackers Editores, 2002. 
CAVALCANTE, Francisco. Faça marketing de guerrilha: soluções criativas, baratas e eficazes para o sucesso da pequena empresa. Belém, PA: Labor, 2003.

GANCHO. Cândida Vilares. Como analisar narrativas. $4{ }^{\text {a }}$ ed. São Paulo: Editora Ática, 2002.

KUNSCH, Margarida Maria Krohling (org.). Obtendo resultados com relações públicas.2. ed. São Paulo: Tomson, 2006.

KOTLER, Philip. Administração de Marketing: a edição do novo milênio. São Paulo, Prentice Hall. 2000.

LEVINSON, Jay Conrad. Marketing de guerrilha. São Paulo: Nova Cultural LTDA, 1989.

MARIE, M. Lendo as imagens do cinema. SP: Senac, 2009.

MORAES, Roque. Análise de conteúdo. Revista Educação, Porto alegre, 1999.

NASCIMENTO, Iara Marques. Gerenciamento de Crise: identificar, planejar e prevenir. Juiz de Fora, 2007. Trabalho de Conclusão de Curso, apresentado como requisito para obtenção de grau de Bacharel em Comunicação Social da Faculdade de Comunicação da UFJF. Disponível em: <http://www.ufjf.br/facom/files/2013/04/IaraMarquesdoNascimento.pdf >. Acesso em: 11 de agosto de 2018.

RIES, Al; TROUT, Jack. Marketing de Guerra. Tradução Auriphebo Berrance Simões. São Paulo: McGraw-Hill, 1986.

RODRIGUES, Cristiano Borges. Planejamento de Campanha Publicitária: o passo-a-passo que ninguém segue. São Paulo: Baraúna, 2010.

SANT'ANNA. Armando. Propaganda - Teoria, técnica e prática da comunicação. $7^{\mathrm{a}} \mathrm{ed}$. São Paulo, Pioneira, 1998.

SANTAELLA, Lúcia. A crítica das mídias na entrada do século XXI. In: PRADO, José Luiz Aidar (org.) Crítica das práticas midiáticas: da sociedade de massas às ciberculturas. São Paulo: Hackers Editores, 2002.

SAMPAIO. Rafael. Propaganda de A a Z. $4^{\text {a }}$ ed. Rio de Janeiro: Elsevier, 2013.

SIMÕES, Eloy. Contato Imediato com Atendimento em Propaganda. Editora Globo. São Paulo,1992.

SEABRA, Rodrigo. Renascença: a série de TV no século XXI.1.ed. Belo Horizonte: Autêntica Editora,2016. 
Empreendedor, Publicitário e Designer. Mestrado em andamento em Linguística Aplicada pela Universidade de Taubaté - UNITAU. Pós-Graduado em Comunicação, Semiótica e Linguagens Visuais pela Braz Cubas Educação. Bacharel em Publicidade e Propaganda pela Universidade de Taubaté, Atua no mercado publicitário como criativo e planner.

Vânia de Moraes

Pós-doutoranda pela Universidade Federal do Rio Grande do Norte - UFRN. Doutora em Comunicação e Semiótica na PUCSP. Mestre em Linguística Aplicada pela Universidade de Taubaté UNITAU. Pós-Graduada em Comunicação Social e Marketing e Comercio Exterior pela Universidade de Taubaté. Docente efetiva da Universidade de Taubaté no Programa de Mestrado em Linguística Aplicada e na Graduação nas áreas de Comunicação, Estética e Arte.

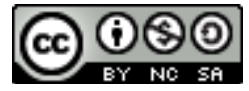

Esta obra está licenciada com uma Licença

Creative Commons Atribuição-NãoComercial-CompartilhaIgual 4.0 Internacional 